\title{
Laboreal
}

Volume 15 №2 | 2019

Varia

\section{Bélgica, 24 de diciembre de 1963: reconocimiento de la silicosis como enfermedad profesional}

\section{Eric Geerkens}

\section{(2) OpenEdition \\ 1 Journals}

Edición electrónica

URL: http://journals.openedition.org/laboreal/15317

ISSN: 1646-5237

Editor

Universidade do Porto

\section{Referencia electrónica}

Eric Geerkens, «Bélgica, 24 de diciembre de 1963: reconocimiento de la silicosis como enfermedad profesional », Laboreal [En línea], Volume 15 №2 | 2019, Publicado el 01 diciembre 2019, consultado el 14 septiembre 2020. URL : http://journals.openedition.org/laboreal/15317

\section{Este documento fue generado automáticamente el 14 septiembre 2020.}

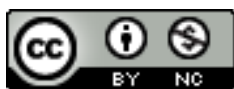

Laboreal está licenciado com uma Licença Creative Commons - Atribuição-NãoComercial 4.0 Internacional. 


\title{
Bélgica, 24 de diciembre de 1963: reconocimiento de la silicosis como enfermedad profesional
}

\author{
Eric Geerkens
}

1 La ley del 24 de diciembre de 1963 pone fin a casi cuatro décadas en las que Bélgica se destacó por su sistema de indemnización de enfermedades profesionales. Esta ley va a modificar profundamente otra ley de 1927, criticada desde su aprobación, e incluir la indemnización de la silicosis de los mineros, hasta entonces excluida de la ley, para ser considerada en el marco de la jubilación anticipada por discapacidad.

\section{Características y fragilidades de la ley del 24 de julio de 1927 sobre la indemnización de los daños causados por enfermedades profesionales}

2 Tal como en numerosas economías industrializadas, la indemnización por enfermedades profesionales surge posteriormente a la de los accidentes de trabajo debido a la especial dificultad de atribución de la responsabilidad. La ley belga de 1927, "una de pocas leyes que han obtenido unanimidad en el Parlamento", tiene un carácter meramente transaccional y no debe ser de ninguna manera considerada una "gran victoria" de los trabajadores, aunque las organizaciones sindicales hayan conseguido que los patronatos fuesen reconocidos como los únicos responsables de esas enfermedades profesionales y, por eso mismo, los únicos a financiar la indemnización.

El reducido ámbito de aplicación de la ley (las únicas tres enfermedades contempladas son las incluidas en el Convenio Internacional del Trabajo no 18 de 1925) fue, en teoría, atenuado por la perspectiva de una ampliación de la lista de enfermedades objeto de indemnización de la cual una sección del Fondo de Previsión de las Victimas de Enfermedades Profesionales ha quedado específicamente encargada, en concreto, la Comisión Técnica. Sin embargo, los patronatos mantienen ahí una garantía substancial 
en la aprobación de las decisiones de esa comisión técnica. La inclusión de una enfermedad en la lista exigía mayorías específicas : o el voto de los tres médicos que integran la Comisión o el voto de representantes de cada uno de los grupos. Teniendo en cuenta que la composición de esa comisión incluía siempre un médico de empresa, el patronato disponía así de un derecho de veto, caso se impusiera una disciplina de voto. Una vez que la ley belga se basa en una lista doble, las enfermedades consideradas profesionales y las industrias que causan exposición, el veto de la Comisión Técnica podría incidir en cualquier una de estas vertientes.

4 La ley cumple el principio de la responsabilidad colectiva por industria causadora de exposición, pero el patronato defendió desde el inicio que "los grupos industriales responsables de la asunción de los costes de los accidentes deben estar extremadamente bien definidos", defendiendo una diferenciación entre las subindustrias causadoras siempre que sea factible, por ejemplo, dentro de la misma empresa, entre las distintas actividades productivas. Esta delimitación restrictiva de la responsabilidad ha originado inmediatamente dificultades prácticas en la recaudación de las cotizaciones, generando una gran heterogeneidad de escalones de cotización y problemas de financiación en los casos en que la industria es de pequeña dimensión o de alto riesgo. A un patronato con una visión restrictiva en términos de la atribución de la responsabilidad, los empleados dirigentes del Fondo de Previsión contrapusieron una forma de solidaridad que obligaba a que el pago de las indemnizaciones fuese soportado por todo el patronato, lo que estuvo en vigor desde 1941. Esto resultó, durante mucho tiempo, en protestas de las empresas que se vieron obligadas a pagar más que los costes de los daños que causaban.

5 Puesto que la responsabilidad de las empresas causadoras de exposición al riesgo se basaba en la declaración del respectivo patronato, las constantes sub-declaraciones privaron el Fondo, sin medios de control adecuados, de una parte significativa de los ingresos que le eran debidos.

Con unos medios financieros estructuralmente insuficientes, las indemnizaciones a las victimas acaban siendo en número reducido : a lo largo de los cerca de treinta y cinco años de actividad, el Fondo solamente indemnizó a 5174 víctimas de las 13190 declaradas, o sea, un porcentaje medio de aceptación del $39 \%$ durante todo ese período. La evaluación de la discapacidad será también muy débil : entre 1930 y 1937, en el $85 \%$ de los casos fue fijada por debajo del $50 \%$ de discapacidad (Moldaver, 1939, p. 130).

7 La situación permanentemente deficitaria del Fondo le impedirá de seguir con una política de prevención basada en incentivos financieros, hasta el punto de la responsabilización colectiva por cada uno de los ramos llevar a comportamientos oportunistas.

8 A la voluntad de los sindicatos de que fuese únicamente el patronato a hacerse cargo de las indemnizaciones por enfermedades profesionales, esta industria respondió que solo aceptaría pagar los costes de las enfermedades profesionales de las que fuese el único responsable. Estas posiciones de principio y las correspondientes implicaciones técnicas contribuyeron a una cierta paralización del Fondo, cuya reforma fue aplazada por la decisión de no incluir en este la silicosis de los mineros y por la dificultad de revertir esta situación. 


\section{El acuerdo Delattre de 1937 para los trabajadores mineros}

9 En el marco de la elaboración de la ley de 1927, el patronato de la industria minera del carbón fue el único que consiguió hacer oír una fuerte oposición y ha logrado que ni el nistagmo ni la anquilostomiasis ni el enfisema pulmonar figuraran en la lista de las enfermedades susceptibles de indemnización.

10 Cuando, en 1934, la Oficina Internacional del Trabajo (BIT) propuso la inclusión de la silicosis en la lista de las enfermedades profesionales susceptibles de indemnización ${ }^{[1]}$, los patronatos de esa industria no pararon de intentar eximir las empresas mineras del carbón de la obligación de indemnizar a las patologías respiratorias de los mineros como enfermedades profesionales. Llegaron incluso a financiar un gran estudio con el fin de probar la inexistencia de la silicosis en el sentido estricto que había sido aprobado en una conferencia de la Oficina Internacional del Trabajo celebrada en Johannesburgo en 1930. Las huelgas de 1936 van, sin embargo, a plantear una vez más la cuestión de la silicosis en la Comisión Técnica del Fondo de Previsión. El presidente de esta comisión, presintiendo las trabas que la referencia a la silicosis podría plantear, propuso que esa palabra no fuese utilizada, pero antes la categoría genérica de “neumoconiosis» que facilitaba la inscripción en la lista de las enfermedades susceptibles de indemnización. La probabilidad de incluir a las minas de carbón en las industrias originadoras de neumoconiosis aumentaba. $Y$ fue entonces que el patronato conjeturó una solución alternativa.

11 Se celebró un acuerdo entre la Federación patronal y el Ministro del Trabajo, él mismo antiguo presidente de la principal central sindical de mineros, en el que se contemplaba el derecho a la jubilación anticipada por discapacidad en el caso de neumoconiosis, que se financiaría con un aumento de las cotizaciones de los trabajadores y empleadores. Esta decisión, transpuesta a la ley, ha permitido, entre otras cosas, indemnizar a un mayor número de víctimas, cuyas pensiones fueron revisadas, pero sobre todo refinanciar el mismo Fondo Nacional de Pensiones de los Trabajadores Mineros que había sido cogido por las medidas de racionalización que además de privarlo de las cotizaciones de los cerca de 50000 mineros despedidos, lo llevaron a incluir una enfermedad de proporciones desconocidas en esa época: la neumoconiosis de los mineros, más conocida por silicosis en Bélgica (Geerkens, 2009).

12 Este acuerdo estuvo en vigor de 1937 hasta 1963. No obstante, las resoluciones aprobadas por los congresos sindicales a favor de una indemnización por enfermedad profesional, no habrá grandes exigencias en ese sentido hasta la catástrofe de Marcinelle en 1956 ( 262 muertos, de los cuales 136 italianos). El tema se vuelve a discutir en el ámbito de la contratación colectiva (en la Comisión Mixta Nacional de la Industria Minera); los sindicatos se atienen entonces al esencial del acuerdo de 1937. De hecho, ese acuerdo facilita el derecho a una indemnización mediante la noción de "incapacidad para trabajar bajo tierra y en la superficie", sin cualquier referencia a una condición específica o grado de discapacidad. Esta medida no conlleva pesados procesos de evaluación y pocas veces da lugar a litigios importantes. En ausencia de cualquier mención al grado de discapacidad, el minero discapacitado tiene derecho a la pensión por entero, calculada del mismo modo que el régimen general de pensiones (Geerkens, 2014). 

sindicatos más grandes por la indemnización de la silicosis, la perspectiva de cierres masivos de minas que amenazan dejar sin amparo mineros enfermos sin derecho a indemnización por insuficiencia de tiempo de trabajo en el subsuelo, de conformidad con la ley de 1937 - va a conducir a una reducción del tiempo de exposición, que pasa de 10 para 5 años.

14

\section{apoyadas, por un lado, por su gobierno (la ley Bitossi que indemniza a los mineros italianos enfermos que regresan a Italia) y, por otro, por las fuerzas progresistas belgas y aún por la integración económica europea mediante la CECA y la CEE (seguridad social de los trabajadores migrantes) para, por fin, llegar a la revisión del régimen de las enfermedades profesionales en 1963. \\ 3. Las características generales de la Ley de 24 de diciembre de 1963}

La revisión concomitante de la ley de 1927 y de la indemnización de la silicosis tardó mucho tiempo en completarse y fue con mucha dificultad que las organizaciones sindicales y sus intermediarios políticos contrarrestaron los varios medios y estrategias dilatorias del patronato. Esa lentitud se debió en gran medida a la importancia vital del carbón como principal fuente de energía industrial y domestica hasta el inicio de la década de 1960.

La ley aprobada en diciembre de 1963 conducirá a una doble reforma : por un lado, la integración de las enfermedades profesionales en el régimen general de la seguridad social y la financiación del nuevo Fondo de Enfermedades Profesionales mediante una contribución pagada por todos los patronatos; por otro, la inclusión de la silicosis de los mineros en la lista de las enfermedades profesionales. Esta inclusión se logró solamente bajo la condición de que el Estado se comprometiera a asumir el $50 \%$ de los costes de las indemnizaciones, una coparticipación que sería aumentada para el $65 \%$ en 1970. Es, por lo tanto, toda la sociedad la que asumirá los costes para la salud de una actividad que está en las manos del sector privado, ya que en Bélgica las minas de carbón nunca han sido nacionalizadas. Las indemnizaciones de la silicosis representan el $87,5 \%$ del total de las indemnizaciones pagadas durante los primeros veinte y cinco años de funcionamiento del nuevo Fondo de Enfermedades Profesionales, y constituyeron la principal actividad de este organismo (Ugeux, 1995, p. 12).

\section{BIBLIOGRAFÍA}

Geerkens, E. (2009). Quand la silicose n'était pas une maladie professionnelle. Genèse de la réparation des pathologies respiratoires des mineurs en Belgique (1927-1940). Revue d'histoire moderne et contemporaine, 56(1), 127-141. https://doi.org/10.3917/rhmc.561.0127

Laboreal, Volume 15 N² | 2019 
Geerkens, E. (2014). La négociation collective d'une maladie professionnelle : la pneumoconiose des ouvriers mineurs en Belgique (c. 1937- c. 1970). In J. Rainhorn (Dir.), Santé et travail à la mine, XIX-XXIe siècles (pp. 59-79). Villeneuve d'Ascq : Presses Universitaires du Septentrion.

Moldaver, J. (1939). Le problème social des maladies professionnelles et sa solution en droit belge. Bruxelles : Falk.

Ugeux, J. (1995). L'assurance contre les maladies professionnelles. In Ministère de la prévoyance sociale : Cinquante ans de sécurité sociale... et après ? vol. 5 : Quand le travail nuit à la santé (pp. 11-42). Bruxelles : Bruylant.

\section{NOTAS}

1. Convenio $n^{\circ} 42$ sobre las enfermedades profesionales (revisado en 1934), que entró en vigor el 17 de junio de 1936.

\section{AUTOR}

\section{ERIC GEERKENS}

Département des sciences historiques. Faculté de Philosophie et Lettres. Université de Liège. Quai Roosevelt, 1B (bât A4) - 4000 Liège, Belgique

E.Geerkens@uliege.be 